\title{
PENGEMBANGAN SISTEM JARINGAN AIR BERSIH DI KECAMATAN DULLAH SELATAN KOTA TUAL PROVINSI MALUKU
}

\author{
Nenny Roostrianawaty ${ }^{1}$, Zachro Bugis ${ }^{2}$ \\ ${ }^{1}$ Dosen, Jurusan Teknnik Sipil, ITN Malang, Jl. Bendungan Sigura-gura No.2 Malang \\ ${ }^{2} J u r u s a n$ Teknnik Sipil, ITN Malang, Jl. Bendungan Sigura-gura No.2 Malang \\ Email: nennyroos.nr@gmail.com
}

\begin{abstract}
South Dullah sub-district is one of the district located in the city of Tual Maluku Province with an average annual population growth of $3.5 \%$ with a population at 3,5 the end of 2018 of 50.523 souls. Clean water services in South Dullah District in 2018 amounted to $55 \%$ of the population who have utilized evu springs with a discharge of $1631 / \mathrm{dt}$, making it possible to develop a clean water distribution network to meet the needs of clean water in the coming year. From the results of the analysis obtained an increase in clean water services from 2018 by $55 \%$ to $85 \%$ in 2034 where the increase in service percentage is not very large due to consideration of the availability of existing water sources. For the plan to develop the pipeline system using a pipe diameter of $150 \mathrm{~mm}$ with experimental simulation using the Watercad V8i program obtained simulation results that meet pressure control at peak hours. Besides the price is more economical.
\end{abstract}

\section{Keywords : network development, clean water, WaterCad V8i}

\begin{abstract}
ABSTRAK
Kecamatan Dullah Selatan merupakan salah satu kecamatan yang berada di Kota Tual Provinsi Maluku dengan rata-rata pertumbuhan penduduk per tahunnya sebesar 3,5\% dengan jumlah penduduk pada akhir tahun 2018 sebesar 50.523 jiwa. Pelayanan air bersih di Kecamatan Dullah Selatan pada tahun 2018 sebesar 55\% dari jumlah penduduk yang mana telah memanfaatkan sumber mata air Evu dengan debit 163 1/dt, sehingga memungkinkan untuk dilakukannya pengembangan jaringan distribusi air bersih guna memenuhi kebutuhan air bersih pada tahun yang akan datang. Dari hasil analisa diperoleh peningkatan pelayanan air bersih dari tahun 2018 sebesar $55 \%$ menjadi $85 \%$ pada tahun 2034 dimana peningkatan prosentase pelayanan tidak terlalu besar dikarenakan pertimbangan ketersediaan sumber air yang ada. Untuk rencana pengembangan sistem jaringan pipa menggunakan pipa berdiameter $150 \mathrm{~mm}$ dengan simulasi percobaan menggunakan program Watercad V8i didapatkan hasil simulasi yang memenuhi kontrol tekanan pada jam puncak. Selain itu harganya lebih ekonomis.
\end{abstract}

Kata Kunci : pengembangan jaringan, air bersih, WaterCad V8i

\section{LATAR BELAKANG}

Kota Tual merupakan pemekaran dari Kabupaten Maluku Tenggara pada tanggal 10 Juli 2007 berdasarkan Undang-Undang Republik Indonesia Nomor 31 tahun 2007 tentang pembentukan kota Tual di Provinsi Maluku. Kota Tual dapat dikatakan sebuah kota dengan usia masih sangat muda sehingga perlu adanya perbaikan pada setiap instansi termasuk system distribusi air bersihnya.

Ketersediaan air bersih sangat penting untuk meningkatkan kesehatan masyarakat Kota Tual, namun demikian perlu dilakukan pengembangan jaringan distribusi air bersih terutama daerah - daerah yang tidak terlayani air bersih. Jumlah penduduk Kota Tual 86.531 jiwa, dan yang terlayani air bersih saat ini baru 55\% saja dari jumlah penduduk. Sumber air baku air bersih Kota Tual berasal dari mata air Evu. (Sumber PDAM Maren Kota Tual).
Kecamatan Dullah Selatan merupakan salah satu dari lima kecamatan yang berada di Kota Tual, jumlah penduduk Kecamatan Dullah Selatan pada akhir tahun 2018 sebesar 50.523 jiwa dan jumlah pelanggan yang terlayani air bersih pada saat ini berkisar 5.558 unit SR (Sambungan Rumah) atau baru $55 \%$ dari jumlah penduduk Kecamatan Dullah Selatan. Mata air Evu berproduksi 163 lt/dt dimanfaatkan sebagai sumber air baku untuk daerah layanan Kecamatan Dullah Selatan, dan sebagian masyarakat belum terlayani air bersih, Masyarakat yang tidak terlayani oleh PDAM memenuhi kebutuhan air bersih dari PAH (Penampung Air Hujan), sumur dan membeli air dari swasta yang disuplai melalui mobil tangki dimana sumber air berasal dari sumur sumur dangkal yang kualitasnya kurang memenuhi persyaratan untuk dikonsumsi sebagai air bersih. Berdasarkan kondisi tersebut maka masih perlu dilakukan upaya pengembangan jaringan air bersih untuk memenuhi kebutuhan masyarakat. Sumber air Evu dengan jumlah produksi yang cukup besar tentu sangat 


\section{Jurnal Sondir \\ Program Studi Teknik Sipil S1, ITN MALANG}

berpotensi untuk dilakukan pengembangan system jaringan pelayanan air bersih Kota Tual.

Seiring dengan laju pertumbuhan penduduk di Kecamatan Dullah Selatan tentunya sangat berpengaruh terhadap kebutuhan air bersih, dimana Kota Tual terus melakukan pengembangan jaringan pelayanan air bersih setiap tahunnya yang bertujuan untuk meningkatkan kesejahteraan masyarakat, agar penyediaan air bersih di Kecamatan Dullah Selatan dapat berbanding lurus dengan laju pertumbuhan penduduk setiap tahunnya.

\section{TINJAUAN PUSTAKA}

\section{Tinjauan Penelitian Terdahulu}

Penelitian I Wayan Satupa (Februari, 2009) yaitu "Studi Potensi Pengembangan Sumber Daya Air di Kota Ampana Sulawesi Tengah". Penelitian ini bertujuan untuk mengetahui sumber air untuk memenuhi kebutuhan air minum di Kota Amapana dan memilih alternatif sumber air yang paling optimal dari potensi sumber daya air yang ada. Metode yang digunakan yaitu survey pendahuluan untuk mengumpulkan data yang dibutuhkan, lalu pengolahan data dengan menggunakan rumus - rumus empiris dari kajian pustaka. Kesimpulan yang didapat dari penelitian ini menunjukan bahwa jika air sungai Ampana dan Sungai Sunsarino saja digunakan untuk kebutuhan air minum, maka sampai proyeksi tahun 2007 belum mampu untuk mencukupi kebutuhan air kota Ampana.

Menurut Emil Salim (1985), masalah air bersih yang menjadi tantangan di masa depan adalah :

1. Penyelamatan air dari eksploitasi secara berlebihan dan pencemaran yang semakin meningkat baik itu air sungai, air danau, air rawa maupun air laut.

2. Permintaan air semakin meningkat didorong oleh pertumbuhan penduduk dan keperluan pembangunan seperti air minum, irigasi, perikanan, industri dan sebagainya,

3. Kualitas air yang ada cenderung menurun sebagai akibat dari meningkatnya pencemaran air. Kondisi ini disebabkan karena pembuangan air limbah ke sungai, tanah dan laut

\section{Sumber Air Baku}

Pemanfaatan sumber daya air yang dipergunakan untuk daerah layanan Kecamatan Dullah Selatan berasal dari mata air Evu dengan kapasitas debit 1.299 liter/detik namun saat ini baru dimanfatkan untuk air bersih sebesar 50 liter/detik. Setelah air baku dari sumber telah memenuhi kualitas air bersih sesuai dengan baku mutu yang ditetapkan di Indonesia, yakni KEPMENKES-RI Nomor 907/ MENKES/ SK/VII/ 2002 dan PERMENKES- RI Nomor 492/MENKES/ PER/IV/2010 tentang persyaratan kualitas air minum dan pengawasan kualitas air minum, kemudian air tersebut didistibusikan ke pelanggan melalui reservoir, dan pipa distribusi sehingga dapat dikonsumsi oleh pelanggan melalui sambungan rumah dan hidran umum.

\section{Kualitas Air Baku}

Mengingat betapa pentingnya air bersih untuk kebutuhan manusia, maka kualitas air harus memenuhi beberapa persyaratan yaitu tidak berasa, tidak berwarna, dan tidak berbau.

Standar kualitas air baku dibedakan dalam kategori yaitu

1. Golongan A, yaitu air yang langsung digunakan sebagai air minum tanpa pengolahan

2. Golongan B, yaitu air yang dapat digunakan sebagai air minum dan keperluan rumah tangga, tetapi tidak sesuai untuk golongan A.

3. Golongan $\mathrm{C}$, yaitu air baik digunakan untuk perikanan, peternakan dan keperluan lainnya, tetapi tidak sesuai untuk golongan A dan B.

\section{Proyeksi Jumlah Penduduk}

Perkembangan penduduk merupakan salah satu faktor penting dalam perencanaan kebutuhan air bersih di masa yang akan datang. Analisa perkembangan penduduk ini digunakan untuk memperkirakan tingkat pelayanan air bersih yang diterima oleh masyarakat.

Hampir di tiap - tiap negara metode proyeksi yang dipakai adalah berbeda - beda karena tiap negara harus menyesuaikan dengan situasi dan kondisi daerah masing - masing. Tingkat pertumbuhan penduduk suatu selain dipengaruhi oleh faktor budaya dan politik juga dipengaruhi oleh faktor ekonomi.

Di Indonesia telah banyak metode yang digunakan untuk menghitung tingkat pertumbuhan penduduk, keadaan ini disebabkan karena Indonesia terdiri dari bermacam macam suku dan budaya yang berbeda, selain itu keadaan ekonomi Indonesia masih tergolong dalam negara yang berkembang yang pendapatan perkapitanya masih sulit ditetapkan secara pasti.

\section{Metode Aritmatik}

Metode ini digunakan bila tidak mengetahui data tentang komponen pertambahan penduduk. Dalam metode ini yang digunakan hanya jumlah penduduk keseluruhan, Perhitungan pertambahan penduduk secara Aritmatik ialah pertumbuhan jumlah penduduk setiap tahun. Rumus :

$\operatorname{Pn}=\operatorname{Po}(1+\mathrm{r} . \mathrm{n})$

Dengan :

Pn = Jumlah penduduk setelah tahun ke-n (jiwa)

Po = Jumlah penduduk saat ini (jiwa)

$\mathrm{n}=$ Jumlah tahun proyeksi (tahun)

$r$ = Angka pertumbuhan penduduk per tahun (\%)

\section{Metode Geometrik}

Pertumbuhan secara geometrik adalah pertumbuhan penduduk yang menggunakan dasar bunga - bunga (bunga majemuk). Jadi pertumbuhan penduduk dimana angka pertumbuhan (rate of growth $=r$ ) adalah sama untuk setiap tahun. 
Rumus :

$\mathrm{Pn}=\mathrm{Po} .(1+\mathrm{r}) \mathrm{n}$

Dengan :

Pn = Jumlah penduduk setelah tahun ke-n (jiwa)

Po $=$ Jumlah penduduk saat ini (jiwa)

$\mathrm{n}$ = Jumlah tahun proyeksi (tahun)

$\mathrm{r}$ = Angka pertumbuhan penduduk per tahun (\%)

\section{Metode Eksponensial}

Perkiraan jumlah penduduk berdasarkan metode eksponensial dapat didekati dengan persamaan berikut Rumus :

$\mathrm{Pn}=$ Po $\mathrm{x}$ e $\mathrm{r} \mathrm{n}$

Dengan :

Pn = Jumlah penduduk setelah tahun ke-n (jiwa)

Po = Jumlah penduduk saat ini (jiwa)

$\mathrm{n}$ = Jumlah tahun proyeksi (tahun)

$\mathrm{r}$ = Angka pertumbuhan penduduk per tahun (\%)

e = Bilangan logaritma natural

\section{Uji Kesesuaian Metode Proyeksi}

Untuk melakukan uji kesesuaian metode proyeksi jumlah penduduk, maka jumlah penduduk harus diproyeksikan terlebih dahulu dengan menggunakan metode Aritmatik, Geometrik, Eksponensial apabila memiliki koefisien korelasi terbesar dan mendekati +1 maka metode tersebut yang akan dipakai sebagai dasar perencanaan. Rumus perhitungan koefisien korelasi adalah sebagai berikut :

$$
r=\frac{n \cdot \sum_{i=1}^{n} X_{i} \cdot Y_{i}-\sum_{i=1}^{n} X_{i} \cdot \sum_{i=1}^{n} Y_{i}}{\sqrt{\left(n \cdot \sum_{i=1}^{n} X_{i}^{2}-\left(\sum_{i=1}^{n} X_{i}\right)^{2}\right) \cdot\left(n \cdot \sum_{i=1}^{n} Y_{i}^{2}-\left(\sum_{i=1}^{n} Y_{i}\right)^{2}\right)}}
$$

Dengan :

$\mathrm{r}=$ Koefisien korelasi

$\mathrm{n}=$ Jumlah data

$\mathrm{x}=$ Jumlah penduduk setiap tahun dari tahun dasar

$\mathrm{y}=$ Jumlah penduduk tiap tahun hasil proyeksi

\section{Kebutuhan Air Domestik}

Kebutuhan domestik adalah kebutuhan air bersih yang digunakan untuk keperluan rumah tangga dan sambungan kran umum. Jumlah kebutuhan air tersebut ditentukan dari data yang ada berdasarkan karakteristik dan perkembangan konsumen pemakai air bersih. rumah adalah :

Tingkat kebutuhan air bersih untuk sambungan

- 130 - 150 Ltr/hari untuk kategori kota kecil (20.000 - 100.000 jiwa)

- $150-170$ Ltr/hari untuk kategori kota sedang $(100.000-500.000$ jiwa $)$

- 170 - 200 Ltr/hari untuk kategori kota besar (500.000 - 1.000 .000 jiwa)

Jumlah jiwa untuk sambungan rumah adalah

- 5 orang untuk kota kecil

- 6 orang untuk kota sedang

- 8 orang untuk kota besar
Rumus :

$>$ Sambungan Rumah

$=$ Kebutuhan Air Perkapita (130 Lt/org/hri) * 70\% Jumlah Penduduk Yang Dilayani.

$>$ Hidran Umum

$=$ Kebutuhan Air Perkapita (30 Lt/org/hri) * 10\% Jumlah Penduduk Yang Dilayani.

(Sumber : R. K Linsley et. Al. Water Resource Engineering)

\section{Kebutuhan Air Non Domestik}

Kebutuhan air non domestik meliputi kebutuhan sosial dan kebutuhan industri. Jenis fasilitas non domestik tersebut antara lain fasilitas perkantoran, pendidikan, perdagangan, rumah ibadah, dan fasilitas kesehatan. Perhitungan non domestik diperhitungkan berdasarkan presentasi dari kebutuhan domestik dan kategori sebagai berikut 20\% - 30\% untuk kategori kota kecil, kota sedang, kota besar.

Rumus :

30\% * (Kebutuhan Air Sambungan Rumah + Kebutuhan air Hidran Umum).

(Sumber : R. K Linsley et. Al. Water Resource

Engineering)

\section{Fluktuasi Kebutuhan Air}

Kebutuhan air bersih tidak akan selalu sama, tetapi akan selalu berfluktuasi. Pada umumnya kebutuhan air dibagi dengan tiga kelompok :

1. Kebutuhan harian rata - rata

Adalah kebutuhan air untuk keperluan domestik dan non domestik termaksud kehilangan air. Biasanya dihitung berdasarkan kebutuhan akan air rata - rata per orang per hari dihitung dari pemakaian air setiap jam selama sehari (24 jam).

2. Kebutuhan Jam Puncak Maksimum

Adalah pemakaian air tertinggi dalam satu hari. Kebutuhan air pada jam puncak dihitung berdasarkan kebutuhan air harian rata - rata dengan menggunakan faktor pengali.

3. Kebutuhan Puncak Harian Maksimum

Adalah banyaknya air yang dibutuhkan terbesar dalam satu tahun. Kebutuhan harian maksimum dihitung berdasarkan kebutuhan air harian rata - rata dengan faktor pengali sebagai berikut :

Kebutuhan air harian maksimum : 1,15 x kebutuhan air rata - rata.

(Sumber : R. K Linsley et. Al. Water Resource Engineering)

\section{Kehilangan Tinggi Tekan (Head Loss)}

Kehilangan tinggi tekan dalam pipa dapat dibedakan menjadi kehilangan tinggi tekan mayor (major losses) dan kehilangan tinggi tekan minor (minor losses).

$E_{T o t}=$ Energi Ketinggian+Energi Kecepatan + Energi Tekanan

$$
E_{T o t}=\mathrm{h}+\frac{V^{2}}{2 g}+\frac{p}{r w}
$$


Persamaan tersebut dapat dijelaskan dengan gambar 2. 1 di bawah ini :

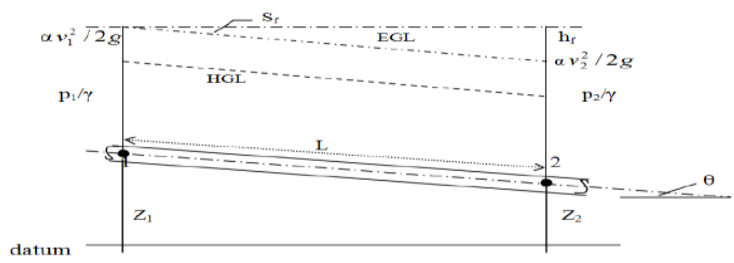

\section{Gambar 2.1 Gradien Hidrolika}

\section{Kehilangan Tinggi Tekan Mayor (Mayor Losses)}

Fluida yang mengalir dalam pipa akan mengalami tegangan geser dan gradien kecepatan pada seluruh medan karena adanya kekentalan. Tegangan geser tersebut akan menyebabkan terjadinya kehilangan tenaga selama pengaliran (Triatmodjo, 1996). Tegangan geser yang terjadi pada dinding pipa merupakan penyebab utama menurunnya garis energi pada suatu aliran (major losses) selain bergantung juga pada jenis pipa. (Sumber: R. K Linsley et. Al. Water Resource Engineering)

\section{Kehilangan Tinggi Tekan Minor (Minor Losses)}

Faktor lain yang juga ikut menambah besarnya kehilangan tinggi tekan pada suatu aliran adalah kehilangan tinggi tekan minor. Kehilangan tinggi tekan minor ini disebabkan oleh adanya perubahan mendadak dari ukuran penampang pipa yang menyebabkan turbulensi, belokan - belokan, adanya katup dan berbagai jenis sambungan (Heasted dalam WaterCad user's guide, 2001). Untuk pipa - pipa yang panjang atau L/D > 1000, kehilangan tinggi tekan minor dapat diabaikan karena nilainya tidak signifikan terhadap kehilangan energy utama. Selain itu faktor pekerjaan manusia (man work) kadang amat berpengaruh terhadap nilai kehilangan tinggi tekan minor, terutama untuk berbagai macam sambungan. (Sumber : R. K Linsley et. Al. Water Resource Engineering)

\section{Hidraulika Aliran Jaringan Pipa Kecepatan Aliran}

Kecepatan aliran dalam pipa yang diijinkan adalah $0,3-6 \mathrm{~m} / \mathrm{det}$, dimana hal ini akan disesuaikan dengan kondisi setempat mengenai kemiringan lahan maupun adanya penambahan tekanan dari adanya pemompaan. Kecepatan tidak boleh terlalu kecil sebab dapat menyebabkan endapan dalam pipa tidak terdorong, selain itu juga diameter pipa jadi berkurang karena adanya endapan itu, dan itu akan membebani biaya perawatan. Sebaliknya, jika kecepatan aliran terlalu tinggi, maka akan berakibat korosi pada pipa dan juga menambah nilai headloss yang berakibat elevasi reservoirnya harus tinggi. Untuk menghitung kecepatan digunakan rumus sebagai berikut :

$$
\begin{aligned}
& Q=A \cdot V \\
& Q=\frac{1}{4} \cdot \pi \cdot D^{2} . V
\end{aligned}
$$

Dimana :

Q : debit aliran $\left(\mathrm{m}^{3} / \mathrm{det}\right)$

$\mathrm{V}$ : kecepatan aliran $(\mathrm{m} / \mathrm{det})$
A : luas basah $\left(\mathrm{m}^{2}\right)$
$\mathrm{D}$ : diameter pipa $(\mathrm{m})$

\section{Hukum Bernoulli}

Air pada pipa selalu mengalir dari tempat yang memiliki tinggi energi yang lebih besar ke tempat yang memiliki energi yang lebih kecil. Hal tersebut dikenal dengan prinsip Bernoulli.

Hukum Bernoulli menyatakan bahwa tinggi energi total pada sebuah penampang pipa adalah jumlah energi kecepatan, energi tekanan dan energi ketinggian yang dapat ditulis sebagai berikut :

$\mathrm{E}_{\mathrm{Tot}}=$ Energi ketinggian + Energi kecepatan + Energi tekanan

$$
\mathrm{E}_{\mathrm{Tot}}=h+\frac{V^{2}}{2 g}+\frac{p}{\gamma_{w}}
$$

Menurut teori Kekekalan Energi dari Hukum Bernoulli apabila tidak ada energi yang lolos atau diterima antara dua titik dalam satu sistem tertutup, maka energi totalnya tetap konstan. Hal tersebut dapat dijelaskan pada gambar 2.3 berikut :

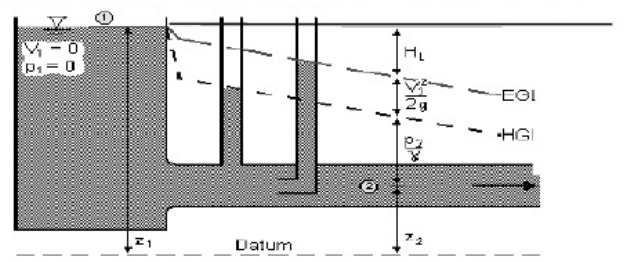

Gambar 2.2 Diagram Energi dan Garis Tekanan Sumber : (Haestad, 2002 : 267)

Hukum Kekekalan Bernoulli pada Gambar 2.3 dapat ditulis sebagai berikut (Haestad, 2002 : 267) :

$$
\mathrm{h}_{1}+\frac{\mathrm{p}_{1}}{\gamma}+\frac{\mathrm{v}_{1}{ }^{2}}{2 \mathrm{~g}}=\mathrm{h}_{2}+\frac{\mathrm{P}_{2}}{\gamma}+\frac{\mathrm{v}_{2}{ }^{2}}{2 \mathrm{~g}}+\mathrm{h}_{\mathrm{L}}
$$

Dengan :

$\frac{\mathrm{p}_{1}}{\gamma}, \frac{\mathrm{p}_{2}}{\gamma}=$ tinggi tekan di titik 1 dan $2(\mathrm{~m})$

$$
\begin{aligned}
& \frac{\mathrm{v}_{1}{ }^{2}}{2 \mathrm{~g}}, \frac{\mathrm{v}_{2}{ }^{2}}{2 \mathrm{~g}}=\text { tinggi energi di titik } 1 \text { dan } 2(\mathrm{~m}) \quad \mathrm{P}_{1}, \mathrm{P}_{2} \\
& =\text { tekanan di titik } 1 \text { dan } 2\left(\mathrm{~kg} / \mathrm{m}^{2}\right) \\
& \gamma_{\mathrm{w}} \quad=\text { berat jenis air }\left(\mathrm{kg} / \mathrm{m}^{3}\right) \\
& \mathrm{v}_{1}, \mathrm{v}_{2}=\text { kecepatan aliran di titik } 1 \text { dan } 2 \\
& \text { (m/det) } \\
& \text { g } \quad=\quad \text { percepatan gravitasi }\left(\mathrm{m} / \operatorname{det}^{2}\right) \\
& \mathrm{h}_{1}, \mathrm{~h}_{2}=\text { tinggi elevasi di titik } 1 \text { dan } 2 \\
& \text { dari garis yang ditinjau }(\mathrm{m}) \\
& \mathrm{h}_{\mathrm{L}} \quad=\text { kehilangan tinggi tekan dalam } \\
& \text { pipa (m) }
\end{aligned}
$$

Pada gambar di atas, terlihat garis yang menunjukkan besarnya tinggi tekan air pada titik tinjauan yang dinamakan garis gradien hidrolis atau garis 


\section{Jurnal Sondir \\ Program Studi Teknik Sipil S1, ITN MALANG}

kemiringan hidrolis. Jarak vertikal antara pipa dengan gradien hidrolis menunjukkan tekanan yang terjadi dalam pipa. Perbedaan ketinggian antara titik 1 dan 2 merupakan kehilangan energi yang terjadi sepanjang penampang 1 dan 2 .

\section{Hukum Kontinuitas}

Air yang mengalir dalam suatu pipa secara terus menerus yang mempunyai luas penampang dan kecepatan akan memiliki debit yang sama pada setiap penampangnya. Dalam persamaan hukum kontinuitas dinyatakan bahwa debit yang masuk ke dalam pipa sama dengan debit yang keluar.

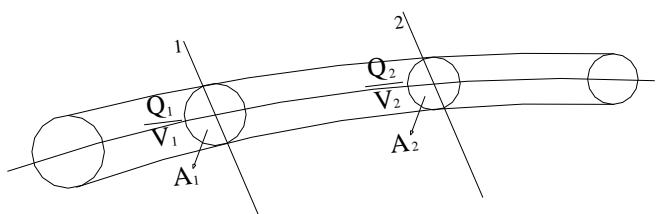

Gambar 2.3 Aliran dengan Penampang Pipa yang Berbeda

Sumber : Triatmodjo (1993:137)

Sehingga dapat dituliskan persamaan:

$$
\begin{aligned}
& A_{1} \cdot V_{1}=A_{2} \cdot V_{2} \\
& \quad \text { atau, } \\
& Q=A . V=\text { konstan }
\end{aligned}
$$

Dengan :

$\mathrm{Q}_{1}, \mathrm{Q}_{2}=$ debit pada potongan 1 dan $2\left(\mathrm{~m}^{3} / \mathrm{det}\right)$

$\mathrm{V}_{1}, \mathrm{~V}_{2}=$ kecepatan pada potongan 1 dan $2(\mathrm{~m} / \mathrm{det})$

$\mathrm{A}_{1}, \mathrm{~A}_{2}=$ luas penampang pada potongan $1 \mathrm{dan} 2\left(\mathrm{~m}^{2}\right)$

Pada aliran percabangan pipa juga berlaku hukum kontinuitas dimana debit yang masuk pada suatu pipa sama dengan debit yang keluar pipa. Hal tersebut diilustrasikan sebagai berikut :

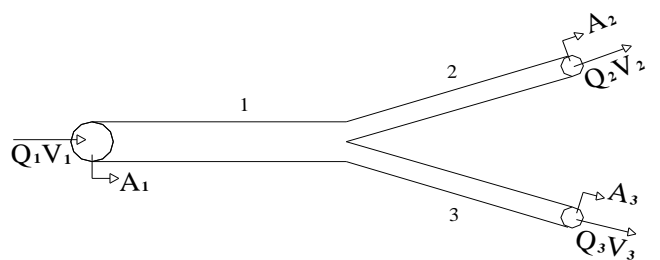

Gambar 2.4 Persamaan Kontinuitas pada Pipa Bercabang Sumber Triatmodjo (1993: 137)

Sedangkan hukum kontinuitas pada pipa bercabang dapat diuraikan sebagai berikut (Triatmodjo, 1996 : 137) :

$$
\begin{aligned}
& \mathrm{Q}_{1}=\mathrm{Q}_{2}+\mathrm{Q}_{3} \\
& \text { Atau } \\
& \mathrm{A}_{1} \cdot \mathrm{V}_{1}=\left(\mathrm{A}_{2} \cdot \mathrm{V}_{2}\right)+\left(\mathrm{A}_{3} \cdot \mathrm{V}_{3}\right) . \\
& \text { dengan: }
\end{aligned}
$$

$\mathrm{Q}_{1}, \mathrm{Q}_{2}, \mathrm{Q}_{3}=$ debit pada potongan 1,2 dan 3 $\left(\mathrm{m}^{3} / \mathrm{det}\right)$

$\mathrm{V}_{1}, \mathrm{~V}_{2}, \mathrm{~V}_{3}=$ kecepatan pada potongan 1,2 dan $3(\mathrm{~m} / \mathrm{det})$

$\mathrm{A}_{1}, \mathrm{~A}_{2}, \mathrm{~A}_{3}=$ luas penampang pada potongan 1 , 2 dan $3\left(\mathrm{~m}^{2}\right)$

\section{Persamaan Hazen - Wiliams}

Rumus ini pada umumnya dipakai untuk menghitung kerugian head dalam pipa yang relatif sangat panjang seperti jalur pipa penyalur air air minum.

Bentuk umum persamaan Hazen - Wiliams, yaitu :

$$
h f=\frac{10.70 \mathrm{Q}^{1.85}}{\mathrm{C}^{1.85} \mathrm{~d}^{4.87}} \mathrm{~L}
$$

Dimana :

$$
\begin{aligned}
& h f=\text { kerugian gesekan dalam pipa }(\mathrm{m}) \\
& \mathrm{Q}=\text { laju aliran dalam pia }\left(\mathrm{m}^{3} / \mathrm{s}\right) \\
& \mathrm{L}=\text { panjang pipa }(\mathrm{m}) \\
& \mathrm{C}=\text { koefisien kekasaran pipa Hazen }- \\
& \text { Wiliams (diperoleh dari table } 2.3) \\
& \mathrm{d}=\text { diameter pipa }(\mathrm{m})
\end{aligned}
$$

\section{Sistem Pengaliran}

Dalam suatu sistem pengaliran jaringan air bersih, terdapat tiga macam sistem pengaliran atau sistem hidraulika yaitu :

\section{Sistem pengaliran gravitasi}

Sistem ini digunakan apabila elevasi sumber air baku atau pengolahan berada jauh diatas elevasi diatas daerah pelayanan dan sistem ini dapat memberikan energi potensial yang cukup tinggi pada daerah pelayanan terjauh.

\section{Sistem pengaliran dengan pompa}

Sistem pompa merupakan sistem pengaliran dengan memompakan air ke dalam jaringan distribusi. Sistem ini digunakan pada elevasi antara sumber air atau instalasi pengolahan air terhadap reservoir distribusi tidak dapat memberikan tekanan yang cukup.

\section{Sistem pengaliran kombinasi}

Sistem ini menggunakan kombinasi antara sistem gravitasi dengan sistem pemompaan. Kombinasi yang lazim digunakan adalah sitem pemompaan untuk menaikkan air pada elevasi tertentu dimana ada reservoir atau ground reservoir untuk menampung air dalam jumlah tertentu untuk kemudian didistribusikan secara gravitasi ke daerah layanan

\section{METODE PENELITIAN}

\section{Metode Pengumpulan Data}

Metode pengumpulan data dilakukan secara:

- Pengumpulan data dari instansi terkait

- Pengumpulan data dari studi literatur

- Pengamatan lapangan.

Dari 3 metode pengumpulan data tersebut maka data yang diperoleh dikelompokkan menjadi 2 bagian :

\section{Data Primer}

Data primer yang diambil meliputi data mengenai keadaan sosial masyarakat dan data kondisi lapangan melalui pendokumentasian. Dengan adanya 
analisis mengenai keadaan sosial masyarakat ini dapat dilihat kemampuan serta kemauan masyarakat untuk menunjang perancangan sistem penyediaan air bersih.

\section{Data Sekunder}

Data sekunder merupakan data pendukung yang diperoleh berdasarkan kajian laporan, jurnal, ataupun data dari instansi terkait antara lain PDAM Kota Tual. Adapun data penunjang yang dibutuhkan adalah sebagai berikut :

1. Data kependudukan dan sosial ekonomi.

2. Data sistem penyediaan air bersih eksisting, meliputi daerah pelayanan, tingkat pelayanan, kapasitas produksi eksisting, dan rencana pengembangan.

3. Data sumber air baku yang akan digunakan, meliputi kualitas, kuantitas, dan kontinuitas, serta pemanfaatan saat ini.

4. Peta lokasi air baku dan lokasi penempatan sistem penyediaan air bersih rencana.

5. Peta topografi lokasi sekitar sistem penyediaan air bersih rencana.

\section{Tahap Penelitian}

Pada tahap persiapan penelitian ini, disusun halhal yang berkaitan dengan penelitian yaitu:

a) Studi pustaka, mengumpulkan dan mempelajari literatur serta teori-teori yang berkaitan dengan judul penelitian

b) Pengumpulan data primer dan sekunder. Data primer didapat dengan cara melakukan pengukuran langsung di lapangan pada unit air baku dan produksi.

c) Dari hasil pengumpulan data dilakukan analisis melalui dua tahapan yaitu analisis teknis sistem eksisting dan analisis optimalisasi sistem setelah dilakukan berbagai macam modifikasi dan alternatif pengembangan sistem.

d) Running jaringan eksisting untuk mengetahui permasalahan pada jaringan yang ada, sehingga didapat solusi perbaikan jaringan baik secara teknis maupun ekonomis.

e) Modifikasi jaringan bila hasil running belum optimal sesuai kriteria dan kebutuhan pelayanan dimasa mendatang.

\section{ANALISA DATA DAN PEMBAHASAN}

\section{Proyeksi Calon Pelanggan}

Calon pelanggan yang akan dilayani kebutuhan air bersih berada di Kec. Dullah Selatan, berdasarkan data yang diperoleh pelayanan air bersih difokuskan kepada penduduk setempat perhitungan ini menggunakan 3 metode, yaitu : Metode Geometrik, Aritmatik dan Eksponensial.

\section{Data Jumlah Penduduk}

Jumlah penduduk daerah layanan yang menjadi konsumen, berdasarkan data yang diperoleh dari Kec. Dullah Selatan mulai 2014 - 2018 adalah sebagai berikut
Tabel 4.1 Jumlah Penduduk Kecamatan Dullah Selatan Tahun 2014 - 2018

\begin{tabular}{|c|c|c|}
\hline No & Tahun & $\begin{array}{c}\text { Jumlah Penduduk } \\
\text { (Jiwa) }\end{array}$ \\
\hline 1 & 2014 & 44060 \\
\hline 2 & 2015 & 45266 \\
\hline 3 & 2016 & 46796 \\
\hline 4 & 2017 & 48541 \\
\hline 5 & 2018 & 50523 \\
\hline
\end{tabular}

Sumber : BPS (Badan Pusat Statistik) Kota Tual

Dari data jumlah penduduk (Po) dan presentai kenaikan jumlah penduduk (r) Kecamatan Dullah Selatan sedikitnya 5 tahun terakhir, maka dapat diproyeksikan jumlah penduduk pada tahun-tahun mendatang. Perhitungan angka kenaikan jumlah penduduk rata-rata dan proyeksi penduduk pada tahun 2019, dengan data jumlah penduduk pada tahun terakhir 2018 yang diperoleh dari BPS (Badan Pusat Statistik) Kota Tual sebagai berikut :

Tabel 4.2 Presentase Pertumbuhan Penduduk

Kec. Dullah Selatan

\begin{tabular}{|c|c|c|}
\hline Tahun & Jumlah & $\begin{array}{c}\text { Presentase } \\
\text { Kenaikan } \\
\text { Jumlah } \\
\text { Penduduk ( r ) }\end{array}$ \\
\hline 2013 & Penduduk ( P ) & $2,74 \%$ \\
\hline 2014 & 45266 & $3,38 \%$ \\
\hline 2015 & 46796 & $3,73 \%$ \\
\hline 2016 & 48541 & $4,08 \%$ \\
\hline 2017 & 50523 & $13,93 \%$ \\
\hline \multicolumn{2}{|c|}{ r total $=$} \\
\hline
\end{tabular}

Sumber : Hasil Perhitungan

\section{Uji Kesesuaian Metode Proyeksi Jumlah Penduduk}

Untuk melakukan uji kesesuaian metode proyeksi jumlah penduduk perlu diproyeksikan terlebih dahulu dari tahun dasar 2014 sampai 2018 dengan menggunakan Metode Geometrik, Aritmatik dan Eksponensial (dapat dilihat di tabel 4.6). Setelah itu baru dihitung koefisien korelasi untuk menentukan Metode mana yang akan di pakai sebagai proyeksi jumlah pertumbuhan penduduk.

Tabel 4.6 Proyeksi Jumlah Penduduk Tahun 2018 2034 


\begin{tabular}{|c|c|c|c|}
\hline \multirow{2}{*}{ Tahun } & \multicolumn{3}{|c|}{ Proyeksi Penduduk (Jiwa) } \\
\cline { 2 - 4 } & Geometrik & Aritmatik & Eksponensial \\
\hline 2018 & 52291 & 52291 & 52323 \\
\hline 2019 & 54121 & 54060 & 54186 \\
\hline 2020 & 56016 & 55827 & 56116 \\
\hline 2021 & 57976 & 57596 & 58115 \\
\hline 2022 & 60005 & 59364 & 60185 \\
\hline 2023 & 62105 & 61133 & 62329 \\
\hline 2024 & 64279 & 62901 & 64549 \\
\hline 2025 & 66529 & 64669 & 66848 \\
\hline 2026 & 68858 & 66438 & 69230 \\
\hline 2027 & 71268 & 68206 & 71696 \\
\hline 2028 & 73762 & 69974 & 74249 \\
\hline 2029 & 76344 & 71743 & 76894 \\
\hline 2030 & 79016 & 73511 & 79633 \\
\hline 2031 & 81781 & 75279 & 82469 \\
\hline 2032 & 84644 & 77048 & 85407 \\
\hline 2033 & 87606 & 78816 & 88449 \\
\hline
\end{tabular}

Sumber : Hasil Perhitungan

Pemilihan Metode Proyeksi pertumbuhan penduduk di atas berdasarkan cara pengujian statistik yakni berdasarkan pada nilai-nilai koefisien korelasi.

Rumus korelasi :

$$
r=\frac{n \cdot \sum_{i=1}^{n} X_{i} \cdot Y_{i}-\sum_{i=1}^{n} X_{i} \cdot \sum_{i=1}^{n} Y_{i}}{\sqrt{\left(n \cdot \sum_{i=1}^{n} X_{i}^{2}-\left(\sum_{i=1}^{n} X_{i}\right)^{2}\right) \cdot\left(n \cdot \sum_{i=1}^{n} Y_{i}^{2}-\left(\sum_{i=1}^{n} Y_{i}\right)^{2}\right)}}
$$

Dengan :

$$
\begin{aligned}
& \mathrm{r} \quad \text { : Koefesien korelasi } \\
& \mathrm{n} \quad \text { : Jumlah data } \\
& \mathrm{x} \quad \text { : Jumlah penduduk setiap tahun dari tahun } \\
& \text { dasar } \\
& \mathrm{y} \quad \text { : Jumlah penduduk tiap tahun hasil proyeksi }
\end{aligned}
$$

\begin{tabular}{|c|c|c|c|c|c|c|c|}
\hline Tahun & $\mathrm{n}$ & $\begin{array}{c}\text { Jumlah } \\
\text { Penduduk } \\
\text { (Jiwa) }\end{array}$ & $\mathrm{x}$ & $\mathbf{Y}$ & $\mathrm{XY}$ & $\mathbf{X}^{2}$ & $\mathrm{Y}^{2}$ \\
\hline 2014 & 5 & 44060 & 44060 & 44060 & 1941283600 & 1941283600 & 1941283600 \\
\hline 2015 & & 45266 & 45266 & 45602 & 2064220132 & 2049010756 & 2079542404 \\
\hline 2016 & & 46796 & 46796 & 47198 & 2208677608 & 2189865616 & 22287651204 \\
\hline 2017 & & 48541 & 48541 & 48850 & 2371227850 & 2356228681 & 2386322500 \\
\hline 2018 & & 50523 & 50523 & 50560 & 2554442880 & 2552573529 & 2556313600 \\
\hline \multicolumn{3}{|c|}{ Total } & 235186 & 236270 & 1113985207 & 11088962182 & 11191113308 \\
\hline & & & & & & & \\
\hline
\end{tabular}

Tabel 4.7 Uji Kesesuaian Metode Provelssi Geometrik
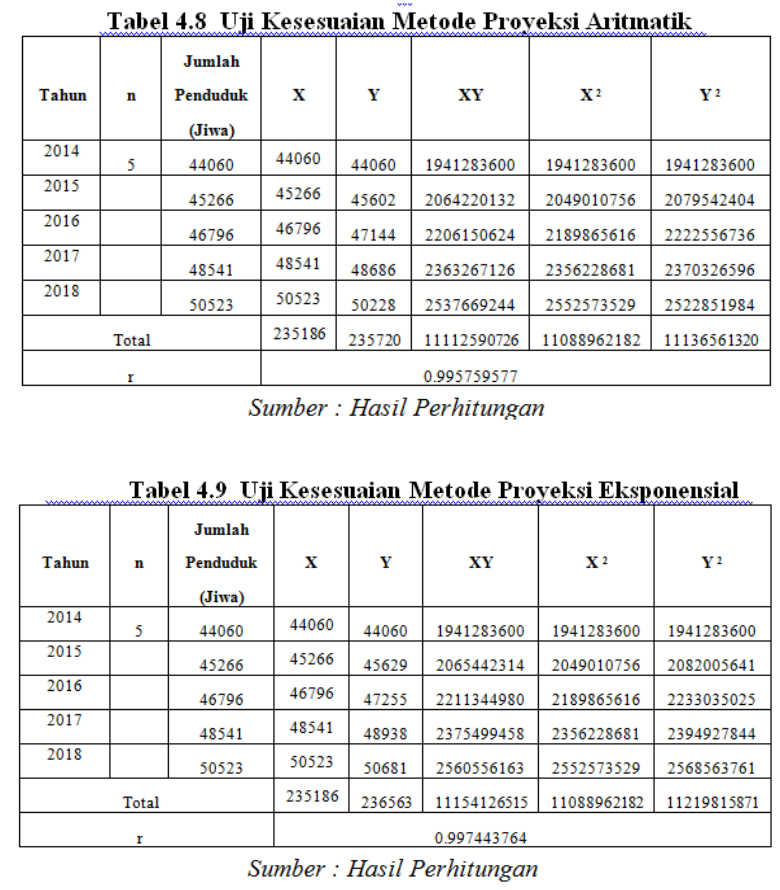

Dari hasil perhitungan koefisien korelasi dengan menggunakan Metode Geometrik, Aritmatik dan Eksponensial maka diperoleh hasil bahwa Metode Eksponensial memiliki korelasi terbesar dan mendekati +1 .

\section{Proyeksi Kebutuhan Air Bersih}

Proyeksi kebutuhan air bersih ditentukan berdasarkan faktor-faktor sebagai berikut :

1. Jumlah penduduk yang dilayani.

2. Pemakaian perkapita per orang.

3. Kebutuhan domestik dan non domestik.

4. Kebocoran air/kehilangan air baik pada system produksi maupun distribusi.

5. Kebutuhan yang belum terpenuhi secara penuh.

6. Peningkatan laju pemakaian air sejalan dengan peningkatan taraf hidup masyarakat.

7. Peningkatan mutu pelayanan.

8. Kebutuhan harian maksimum.

Pada dasarnya kriteria dalam perencanaan dalam system penyediaan air bersih suatu kota disesuaikan dengan kondisi setempat dan mengacu pada standar perencanaan normal.

\section{Analisa Perhitungan Proyeksi Kebutuhan Air Bersih}

Contoh perhitungan untuk tahun 2019 :

1. Total Produksi Air Bersih 143 1/dt

2. Jumlah penduduk Kec. Dullah Selatan tahun $2019=52323$ jiwa

3. Tingkat konsumsi pelayanan
Sambungan Rumah $=5$ jiwa $/ \mathrm{SR}$

4. Pelayanan Kebutuhan Air Bersih pada tahun 2019 dapat dipenuhi sebesar 57\% dari jumlah penduduk.

5. Jumlah Penduduk Yang Dilayani 


\section{Jurnal Sondir \\ Program Studi Teknik Sipil S1, ITN MALANG}

$=\frac{\text { Jumlah penduduk }}{\text { Jumlah jiwa per SR }} *$ Jumlah Pelayanan

$=\frac{52323}{5} * 57 \%=5.965$ unit $* 5=29.825$ jiwa

6. Kebutuhan Air Perkapita sebesar 130 liter/org/hr

7. Kebutuhan Air Domestik (Qd)

Sambungan Rumah

$=$ Kebutuhan Air Perkapita * Jumlah penduduk yang dilayani

$$
=130 * 29.825=3877250 \mathrm{lt} / \mathrm{hr}=44,88
$$

$1 / \mathrm{dt}$

8. Kebutuhan Air Non Domestik (Qn)

Kebutuhan air non domestik diperhitungkan berdasarkan presentasi dari kebutuhan domestik dengan kategori 30\% untu kategori kota kecil, kota sedang dan kota besar.

Jadi kebutuhan air non domestik adalah :

$=30 \% *(\mathrm{Qd})$

$=30 \% * 44,881 / \mathrm{dt}=13,461 / \mathrm{dt}$

9. Total Konsumsi

$=(\mathrm{Qd})+(\mathrm{Qn})=44,88+13,46=58,34 \mathrm{l} / \mathrm{dt}$

10. Kehilangan Air

Kehilangan Air direncanakan 30\% dari produksi

$=30 \% * 58,341 / \mathrm{dt}=17,5 \mathrm{lt} / \mathrm{dt}$

11. Kebutuhan Air Rata - Rata (Qr)

$=\mathrm{Qd}+\mathrm{Qn}+$ Kehilangan Air

$=44,881 / \mathrm{dt}+13,461 / \mathrm{dt}+17,51 / \mathrm{dt}=75,84$ $1 / \mathrm{dt}$

12. Kebutuhan harian maksimum (Qpeak)

Pemakaian air pada harian maksimum diartikan sebagai pemakaian tertinggi pada hari tertentu selama satu tahun.

$=(\mathrm{Qr}) * 1.15$ (faktor harian maksimum)

$=75,84 \mathrm{l} / \mathrm{dt} * 1.15=87,22 \mathrm{lt} / \mathrm{dt}$

13. Fluktuasi Pemakaian Air setiap jam

Pada jam puncak pagi (pukul 06.00)

$=(\mathrm{Qr}) * 1,56=75,84 * 1.56=118,31 \mathrm{lt} / \mathrm{dt}$

Untuk proyeksi kebutuhan air bersih hingga tahun 2034 dapat dilihat ditabel 4.10 berikut:

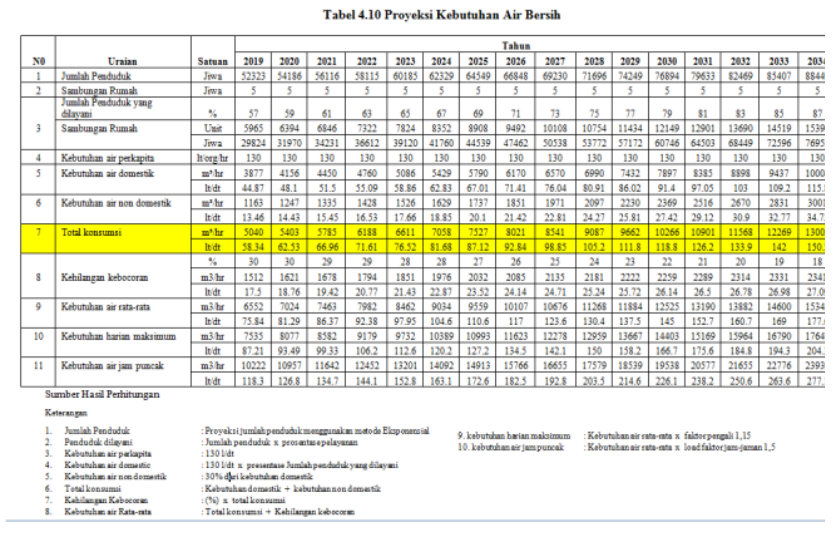

\section{Analisa Kapasitas Reservoir}

Dalam perncanaan distribusi air minum, air dari Instalasi Pengolahan disimpan dalam Reservoir sebelum didistribusikan. Hal ini dilakukan agar pengeluaran air dapat konstan. Penentuan kapasitas reservoir didasarkan pada produksi air sebesar $100 \%$, sehingga produksi dibagi suplai air tiap jam 100/24 dari kebutuhan maksimum dengan menentukan waktu pengisian. Selain itu penentuan kapasitas reservoir juga dipengaruhi oleh fluktuasi dibagi penggunaan air yang setiap jamnya selalu berubah.

\begin{tabular}{|c|c|c|c|c|}
\hline Waktu ( Jam ) & $\begin{array}{c}\text { Produksi } \\
\left(\mathrm{m}^{3}\right)\end{array}$ & $\begin{array}{c}\text { Kebutuhan } \\
\text { Air }\left(\mathbf{m}^{3}\right)\end{array}$ & $\begin{array}{c}\text { Selisih } \\
\left(\mathbf{m}^{3}\right)\end{array}$ & $\begin{array}{c}\text { Komulatif } \\
\text { Isi }\left(\mathbf{m}^{3}\right)\end{array}$ \\
\hline (1) & $(2) x$ & (3) & $(4)=(2-3)$ & $(5)=(5+4)$ \\
\hline $20020-21001$ & 586.8 & 575.064 & 11.736 & 10.296 \\
\hline $21100-2200$ & 586.8 & 363.816 & 222.984 & 233.28 \\
\hline $22 z 00-2300$ & 586.8 & 264.06 & 322.74 & 556.02 \\
\hline $23300-2400$ & 586.8 & 217.116 & 369.684 & 925.704 \\
\hline $2400-0100$ & 586.8 & 146.7 & 440.1 & 1365.804 \\
\hline 210le-ozulen & 586.8 & 176.04 & 410.76 & 1776.564 \\
\hline $22000-0300$ & 586.8 & 217.116 & 369.684 & 2146.248 \\
\hline $2300-0400$ & 586.8 & 264.06 & 322.74 & 2468.988 \\
\hline $24,00-0500$ & 586.8 & 375.552 & 211.248 & 2680.236 \\
\hline $2500-0600$ & 586.8 & 674.82 & -88.02 & 2592.216 \\
\hline $2600-07020$ & 586.8 & 915.408 & -328.608 & 2263.608 \\
\hline 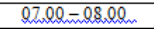 & 586.8 & 897.804 & -311.004 & 1952.604 \\
\hline 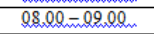 & 586.8 & 827.388 & -240.588 & 1712.016 \\
\hline $2902-1002$ & 586.8 & 821.52 & -234.72 & 1477.296 \\
\hline $1000-1100$. & 586.8 & 809.784 & -222.984 & 1254.312 \\
\hline $11.00-12000$ & 586.8 & 745.236 & -158.436 & 1095.876 \\
\hline $1200-130 l 0$ & 586.8 & 704.16 & -117.36 & 978.516 \\
\hline $1300-1400$ & 586.8 & 668.952 & -82.152 & 896.364 \\
\hline $1400-1500$, & 586.8 & 686.556 & -99.756 & 796.608 \\
\hline $1500-16,0 h$ & 586.8 & 692.424 & -105.624 & 690.984 \\
\hline $1600-1700$, & 586.8 & 715.896 & -129.096 & 561.888 \\
\hline $17200-1800$ & 586.8 & 768.708 & -181.908 & 379.98 \\
\hline $1800-1900$ & 586.8 & 809.784 & -222.984 & 156.996 \\
\hline $19900-2000$, & 586.8 & 733.5 & -146.7 & 10.296 \\
\hline
\end{tabular}

Keterangan :

(2) = Kapasitas Produksi 143 lt/dt : $24=541.8 \mathrm{~m}^{3}$

(3) $=(2) x$ fluktuasi pemakaian air bersi tiap jam.

(4) $=$ Selisih pemakaian (2) $-(3)$

$(5)=$ Komulatif isi $(5+4)$

\section{Kebutuhan Air Bersih Daerah Layanan Kecamatan Dullah Selatan}

Daerah layanan kondisi eksisting pada studi ini dibagi menjadi 9 (sembilan) wilayah daerah pelayanan (zona pelayanan) :

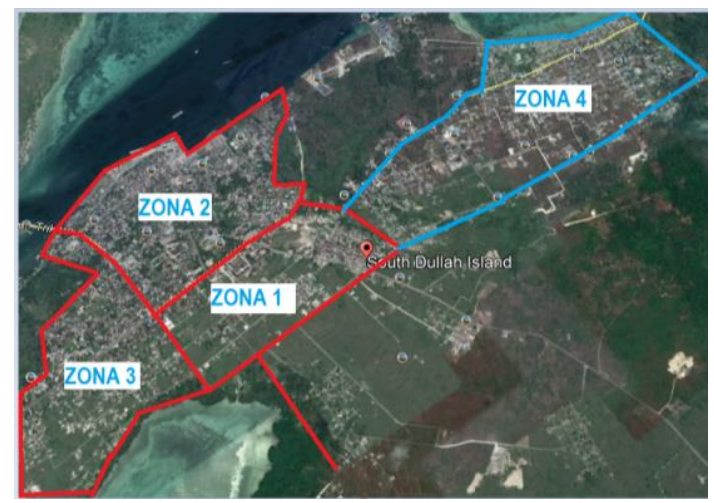

Gambar 4.1 Skema Pelayanan Eksisting Wilayah Studi Sumber: Google Earth 


\section{Jurnal Sondir \\ Program Studi Teknik Sipil S1, ITN MALANG}

Penentuan daerah pelayanan ditentukan berdasarkan jaringan pipa primer yang ada tanpa mengurangi jumlah pelanggan pada kondisi saat ini. Daerah layanan pengembangan yaitu pada zona 4 . Perhitungannya diawali dengan membagi saluran primer menjadi beberapa daerah layanan, mengetahui jumlah pelanggan pada setiap daerah layanan.

Sehingga dengan jumlah pelanggan dikalikan dengan kebutuhan per orang, maka diperoleh kebutuhan air pada masing-masing daerah layanan. Berikut merupakan pembagian daerah layanan dan kebutuhan airnya

\begin{tabular}{|c|c|c|c|c|}
\hline \multirow{2}{*}{ Tona } & $\begin{array}{c}\text { Jumlah } \\
\text { Pelanggan }\end{array}$ & Kebutuhan/Org & Kebutuhan/Org & $\begin{array}{c}\text { Kebutuhan } \\
\text { Air Bersih }\end{array}$ \\
\cline { 2 - 5 } & (orang) & (l/hr) & (l/dt) & (l/dt) \\
\hline $\mathbf{1}$ & 7.576 & 130 & 0.0015 & 11,36 \\
\hline $\mathbf{2}$ & 17.680 & 130 & 0.0015 & 26,52 \\
\hline $\mathbf{3}$ & 15.152 & 130 & 0.0015 & 22,73 \\
\hline $\mathbf{4}$ & 10.115 & 130 & 0.0015 & 15,17 \\
\hline Total & $\mathbf{5 0 . 5 2 3}$ & \multicolumn{5}{|c|}{ Sumber : Hasil Perhitungan } \\
\hline \multicolumn{5}{|c|}{}
\end{tabular}

\section{Keterangan :}

- $\quad$ Total Jumlah Penduduk $=50.523$ Jiwa

- Kebutuhan / Org = $130: 86.400=0.0015$

- Kebutuhan Air Bersih = Jumlah Pelanggan $\mathrm{x}$ Kebutuhan Per Orang

Pengembangan Sistem Jaringan Distribusi Air Bersih

Pada sistem jaringan air bersih di daerah layanan Kecamatan Dullah Selatan menggunakan sistem gravitasi untuk melayani pelanggan dan untuk memenuhi kriteria perencanaan distribusi, ada beberapa kriteria yang harus diperhatikan. Kriteria-kriteria tersebut yaitu tekanan sisa pada titik simpul (junction) berkisar 0,5 - 8 atm untuk pipa PVC, kehilangan tinggi tekan yang diijinkan berkisar $0-15 \mathrm{~m} / \mathrm{km}$ dan untuk kecepatan aliran air dalam pipa itu sendiri berkisar 0,3 - 4,5 $\mathrm{m} /$ det.

Pengembangan pipa ini menggunakan jenis pipa PVC dengan Hazen-Williams $\mathrm{C}=150$, sedangkan diameter pipa pengembangan menggunakan pipa $150 \mathrm{~mm}$.

\section{Pembahasan}

Berdasarkan hasil analisa yang telah dilakukan, maka dapat disimpulkan sebagai berikut :

1. Dari hasil perhitungan uji kesesuaian proyeksi penduduk untuk Kecamatan Dullah Selatan, metode Exponensial yang paling mendekati kebenaran, yaitu koefisien korelasinya mendekati 1 sebesar 0,997443. Metode Exponensial inilah yang akan digunakan untuk memproyeksikan jumlah penduduk Kecamatan Dullah Selatan 15 tahun kedepan.

2. Dari hasil perhitungan kebutuhan air bersih pada tahun 2033 sebesar 150,5 1t/dt. Sedangkan untuk kebutuhan air pada jam puncak yaitu pada pukul 06.00 sebesar $277,1 \mathrm{lt} / \mathrm{dt}$,

3. Dari hasil perhitungan, dibutuhkan kapasitas bangunan Reservoir sebesar $2.700 \mathrm{~m}^{3}$ untuk memenuhi kebutuhan air bersih pada jam-jam puncak.

4. Pengembangan sistem jaringan distribusi air bersih menggunakan pipa berdiameter $150 \mathrm{~mm}$, dimana hasil simulasi yang dilakukan pada jam puncak pukul 06.00 memenuhi control tekanan, untuk kecepatan aliran (velocity) juga memenuhi kontrol kecepatan aliran.

\section{KESIMPULAN DAN SARAN}

\section{Kesimpulan}

Berdasarkan hasil analisa dan perencanaan Pengembangan jaringan distribusi air bersih di Kecamatan Dullah Selatan sampai tahun 2034, maka diperoleh beberapa kesimpulan sebagai berikut :

1. Berdasarkan hasil perhitungan, dilihat dari suplai air sebesar 163 lt/dt masih mampu melayani kebutuhan air bersih di Kecamatan Dullah Selatan sampai tahun 2034

2. Berdasarkan hasil perhitungan, bangunan Reservoir yang ada berkapasitas $2.700 \mathrm{~m}^{3}$, mampu mencukupi kebutuhan jam puncak sampai tahun 2034 sebesar 277 1/dt.

3. Dari hasil simulasi program WaterCad V8i untuk pengembangan sistem jaringan distribusi air bersih di Kecamatan Dullah Selatan dipakai pipa berdiameter $150 \mathrm{~mm}$, karena memenuhi kontrol tekanan.

\section{Saran}

Dari kesimpulan di atas penulis tidak lupa untuk memberikan saran-saran yang bersifat membangun demi kemajuan pelayanan air bersih di Kota Tual.

1. Seiring berjalannya waktu jumlah penduduk di Kecamatan Dullah Selatan terus bertambah maka diharapkan agar PDAM Kota Tual segera mencari sumber air baku baru agar bisa memenuhi kebutuhan air bersih setiap tahunnya.

2. Diharapkan untuk PDAM Kota Tual untuk selalu mengevaluasi kebutuhan air bersih, serta terjun langsung ke lapangan untuk mengetahui apakah pengaliran air dari PDAM sudah tercukupi untuk masyarakat atau belum.

\section{DAFTAR PUSTAKA}

Anonim. 2007. Peraturan Pemerintah Nomor 41 Tahun 2007, tentang Organisasi Perangkat Daerah. Jakarta.

Bentley Methods 2007 User's Guide WaterCAD 8 for Windows WATERBUY CT. USA: Bentley. Press

Djoko Sasongko, 1995 “Teknik Sumber Daya Air" Erlangga, Jakarta

DPU Ditjen Cipta Karya. 1987. Buku Utama Sistem Jaringan Pipa. Diktat Kursus Perpipaan Departemen Pekerjaan Umum Direktoral Jeneral Cipta Karya 
Direktorat Air Bersih. Jakarta :

Departemen Pekerjaan Umum,

ektoral Jenderal Cipta Karya, Direktorat Air

Bersih.

DPU Ditjen Cipta Karya. 1994. Pedoman

Kebijakan Program Pembangunan

Prasarana Kota Terpadu (P3KT).

Hidayat, Muhammad Alvan, Mohammad

Taufiq, and Ery Suhartanto. 2014. Studi

Perencanaan Sistem Penyediaan Air

Bersih Untuk Kecamatan Kubu Kabupaten

Karangasem. Jurnal Teknik Universitas

Brawijaya. Universitas Brawijaya

Kodoatie, 2002 "Hidrolika Terapan (Aliran

pada saluran terbuka dan pipa),

Edisi revisi" Penerbit Andi, Yogyakarta

Mandara, at. all (2013) "melalui penelitiannya mengkaji mengenai community management dalam pengelolaan air pedesaan Tanzania"

Mirumachi an Wykt (2010) "melalui risetnya mengkaji pemberdayaan actor di Afrika Selatan dalam kebijakan pengelolaan air".

Muliakusumah, Sutarsih. 2000. Proyeksi

Penduduk. Jakarta: Fakultas Ekonomi UI.

Priyantoro, Dwi. 1991. Hidraulika

Saluran Tertutup. Malang: Jurusan

Pengairan Fakultas Teknik Universitas

Brawijaya

Ray K Lisley, Joseph B Franzini, 1991,

"Teknik Sumber Daya Air, Jilid II Edisi ke

3”, Erlangga, Jakarta

Tigabu, et.al (2013), “ melalui risetnya mengkaji community participation dalam penyediaan air bersih di Ethopia”.

Totok Sutrisno, C., Dkk., 2002, "Teknologi Penyediaan Air Bersih”, Rineka Cipta, Jakarta

Triatmojo, B. 1996. Hidraulika I, Fakultas

Teknik Universitas

Gajahmada.Yogyakarta.

Triatmodjo, Bambang. 2003. Hidraulika II. Yogyakarta : Penerbit Beta Offset

Triatmodjo, B. (2008). Hidraulika II.

Yogyakarta: Beta Offset.

Streater L Victor dan Wylie Benjamin, 1990, “Mekanika Fluida jilid I', Erlangga, Jakarta

Webber, N. B. 1971. Fluid Mechanics For Civil Engineering, S. I. Edition. London: Chapman and Hall Ltd.

$\mathrm{Yu}$, et.al (2015) "melalui risetnya meneliti permasalahan penyediaan air di Cina"

Yusuf, A. Muri. (2005). Metodologi Penelitian. Padang : UNP Press. www. Bimex.lu 